\title{
Capillary Electrophoresis of Natural Products: Current Applications and Recent Advances
}

Author

Affiliation
Matthias Unger

Institute of Pharmacy and Food Chemistry, Department of Pharmaceutical Chemistry, University of Würzburg, Würzburg, Germany
Key words

- capillary electrophoresis

- capillary electrophoresismass spectrometry

- capillary zone electrophoresis

- field-amplified sample injection

- micellar electrokinetic chromatography

- microemulsion electrokinetic chromatography

- sweeping received Sept. 29, 2008

revised Dec. 23, 2008

accepted February 2, 2009

Bibliography

Dol $10.1055 / \mathrm{s}-0029-1185453$

Published online March 16,

2009

Planta Med 2009; 75: 735-745

(c) Georg Thieme Verlag KG

Stuttgart - New York .

ISSN 0032-0943

\section{Correspondence}

Matthias Unger

Department of Pharmaceutical Chemistry

Institute of Pharmacy and Food Chemistry

University of Würzburg

Am Hubland

97074 Würzburg

Germany

Phone: + 499318885463

Fax: + 499318885494

m.unger@pharmazie.

uni-wuerzburg.de

\section{Abstract}

$\nabla$

Capillary electrophoresis (CE) was introduced as a new analytical technique in the 1970s and rapidly proved to be a powerful tool for the separation and detection of various classes of natural and synthetic compounds. Since the availability of commercially manufactured high-performance instruments, CE represents an interesting alternative to high-pressure liquid chromatography (HPLC), mainly because of its speed and high separation efficiency. In this overview a short description of the basic and widely used CE methods will be given and the applicability of these methods for the analysis of natural products will be discussed. Due to the growing number of publications dealing with $\mathrm{CE}$ or CE/MS of secondary plant metabolites, an exhaustive overview of all current applications cannot be given in this contribution. Therefore, the focus of this mini-review will be on the advances and new aspects of recently published CE methods in natural products analysis.

\section{Introduction $\nabla$}

Capillary electrophoresis (CE) represents one of the most attractive analytical techniques for the rapid qualitative and quantitative analysis of molecules with a wide range of polarity and molecular weight, including small molecules such as drugs but also macromolecules such as proteins or nucleic acids. Because of its versatility and high separation efficiency, CE is an interesting alternative to the widely used reversed-phase high-pressure liquid chromatography (RP-HPLC) and has gained much interest for the analysis of natural products in herbal extracts, pharmaceutical for-

$\begin{array}{ll}\text { Abbreviations } \\ \text { ACN: } & \text { acetonitrile } \\ \text { AcOH: } & \text { acetic acid } \\ \text { CE: } & \text { capillary electrophoresis } \\ \text { CD: } & \text { cyclodextrin } \\ \text { CEC: } & \text { capillary electrochromatography } \\ \text { CE/ESI-MS: } & \text { capillary electrophoresis-electro- } \\ & \text { spray ionisation mass spectrometry } \\ \text { CZE: } & \text { capillary zone electrophoresis } \\ \text { DMF: } & \text { dimethyl formamide } \\ \text { EOF: } & \text { electroosmotic flow } \\ \text { ESI: } & \text { electrospray ionisation } \\ \text { FASI: } & \text { field-amplified sample injection } \\ \text { FESS: } & \text { field-enhanced sample stacking } \\ \text { IsoOH: } & \text { isopropanol } \\ \text { MEKC: } & \text { micellar electrokinetic chromatog- } \\ & \text { raphy } \\ \text { MEEKC: } & \text { microemulsion electrokinetic chro- } \\ & \text { matography } \\ \text { MS; } & \text { mass spectrometry } \\ \text { NACE: } & \text { non-aqueous capillary electropho- } \\ \text { MeOH: } & \text { resis } \\ \text { methanol } \\ \text { THF: } & \text { reversed-migration MEKC } \\ & \text { tetrahydrofuran } \\ & \end{array}$

mulations, and food supplements. Since its introduction in 1979 by Mikkers et al. [1] and in 1981 by Jorgenson and Lukacs [2,3], the popularity of $\mathrm{CE}$ continuously increased so that high-performance CE instruments became rapidly available. Over the years the tremendous progress of this fascinating separation technique has led to a great variety of separation methods and applications that have been outlined in recently published reviews [4-9]. CE has been frequently applied especially for the qualitative and quantitative analysis of secondary plant metabolites in crude plant extracts [10-12]. In the following, a short description of the basic and widely used CE methods 
(e.g., capillary zone electrophoresis [CZE], non-aqueous capillary electrophoresis [NACE], micellar electrokinetic chromatography [MEKC], microemulsion electrokinetic chromatography [MEEKC], and capillary electrochromatography [CEC]) will be given, and the applicability of these methods for the analysis of secondary plant metabolites will be discussed.

\section{Capillary Zone Electrophoresis \\ $\nabla$}

In the absence of an electroosmotic flow (EOF), the migration velocity $v_{\mathrm{i}}$ of a charged molecule $i$ in an electrical field is proportional to the electrophoretic mobility $\mu_{\mathrm{i}}$ and the electrical field strength $E$ (equation $\mathbf{1}$ ):

$\mathrm{V}_{\mathrm{i}}=\mu_{\mathrm{i}} \cdot \mathrm{E}$

The electrophoretic mobility $\mu_{\mathrm{i}}$ is dependent on the net charge $z_{\mathrm{i}} \cdot e_{0}$ and the friction coefficient $6 \cdot \pi \cdot r \cdot \eta$ (equation 2 ):

$\mu_{\mathrm{i}}=\frac{\mathrm{z}_{\mathrm{i}} \cdot \mathrm{e}_{0}}{6 \cdot \pi \cdot \mathrm{r} \cdot \eta}$

Whereas the net charge of a molecule is the result of its $\mathrm{p} K_{\mathrm{a}}$ value and of the $\mathrm{pH}$ value of the electrolyte, the friction coefficient is determined by its size $(6 \cdot \pi \cdot r)$ and the viscosity $(\eta)$ of the running buffer. As the size and shape of a molecule cannot be influenced, the net charge of the analytes can be manipulated by the $\mathrm{pH}$ value of the buffer. Furthermore, if the $\mathrm{p} K_{\mathrm{a}}$ values of the analytes are known, the net charge can be calculated via the dissociation rate using the Henderson-Hasselbalch equation (equation 3):

$\mathrm{pH}=\mathrm{pK}_{\mathrm{a}}+\log \frac{\mathrm{c} \text { (base })}{\mathrm{c}(\text { acid })}$

Ideal candidates for CZE analyses of natural products are permanently charged molecules such as anthocyans, quaternary alkaloids, and sulphated flavonoids. For such molecules, the $\mathrm{pH}$ value of the buffer can be varied over a wide range without loss of the electrophoretic mobility, which is also particularly advantageous for capillary electrophoresis-mass spectrometry (CE/MS). Indeed, CE/MS analyses of anthocyans and quaternary alkaloids have been published frequently [13-17]. If several permanently charged molecules with similar molecular weights have to be analysed, the permanent charge is a disadvantage because all molecules exhibit a very similar mass-to-charge ratio. In this case the selectivity can be tuned by organic solvents and counterions that have a high affinity to the oppositely charged analytes [18].

Because many secondary plant metabolites (e.g., benzoic or cinnamic acids, coumarins, flavonoids) possess phenolic hydroxy groups, they can be analysed with CZE using running buffers with neutral to basic $\mathrm{pH}$ values in the range between 7 and 12. For example, the three major curcuminoids curcumin, demethoxycurcumin, and bis-demethoxycurcumin from Curcuma domestica, Curcuma longa, and Curcuma xanthorrhiza were fully separated and quantified in less than 5 min using a basic running buffer consisting of $20 \mathrm{mM}$ phosphate, $50 \mathrm{mM}$ sodium hydroxide, and $14 \mathrm{mM} \beta$-cyclodextrin ( $\beta$-CD) [19]. Comparable to CEC, MEKC and MEEKC, CE analyses with electrolytes containing cyclodextrins can also be considered electrokinetic chromatography. The addition of $\beta$-CD enhanced the solubility of the curcuminoids and influenced the selectivity because the different stability of the curcuminoid-CD inclusion complexes individually influenced the migration behaviour of the analytes. Curcuminoids with a high affinity to the $\beta$-CD molecules have a lower migration velocity to the anode than do curcuminoids that do not easily form inclusion complexes with $\beta$-CD. For some natural product classes that are not acidic or basic (e.g., sugars, phenolic glycosides), a charge can be created by complexation. Vicinal hydroxy groups of neutral sugars or glycosides with a cis-configuration can form complexes with borate anions, which leads to a migration of the anionic complexes to the anode. In fused silica capillaries and at neutral to basic $\mathrm{pH}$ values, the EOF carries the negatively charged complexes to the cathode. In this case the selectivity of the separation is determined by the stability, size, and molecular geometry of the analyte-borate complexes. This separation principle was frequently applied for the analysis of neutral secondary plant metabolites in the past $[20,21]$. For example, Honda et al. reported the CZE analysis of reducing monosaccharides after derivatisation to their corresponding $\mathrm{N}$-2-pyridylglycamines [20]. The derivatised sugar molecules were separated as their borate complexes using $200 \mathrm{mM}$ borate ( $\mathrm{pH} 10.5)$ as running buffer. Also, Schwaiger et al. separated aldoses and ketoses as their borate complexes using $175 \mathrm{mM}$ borate ( $\mathrm{pH}$ 10.5) as electrolyte [21]. In order to enhance the UV absorption of the sugars, a reductive amination with 4-aminobenzonitrile was performed.

Among the different classes of natural compounds analysed with CZE are alkaloids [16,22-24], anthraquinones [25,26], anthocyans [27,28], carbohydrates [29], catechins [30], coumarins [31,32], flavonoids [33-35], glucosinolates [36], phenolic acids [37], proanthocyanidins [38], red wine pigments [39], saponins [40], and xanthones [41]. Due to the variety of factors influencing the separation selectivity and efficiency in CZE, an extensive discussion on method development strategies cannot be given in this review. Thus, for a comprehensive overview about the optimisation of CZE methods for the analysis of natural products, refer to the recently published review of Li et al. [42].

\section{Non-Aqueous Capillary Electrophoresis} $\nabla$

The first paper dealing with CE separations in a pure non-aqueous medium was written by Walbroehl and Jorgenson in 1984 [43]. Since then, non-aqueous buffer systems have been increasingly applied for the separation of small molecules including secondary plant metabolites [44]. The separation media in nonaqueous capillary electrophoresis (NACE) contain water-miscible organic solvents such as acetonitrile (ACN), dimethyl formamide (DMF), or various alcohols and acidic or basic solvents such as formic acid, acetic acid (AcOH), ammonia, or diethylamine [45]. Because the low conductivity of these buffer media normally results in lower currents compared with aqueous media, the electrolyte concentration and the electrical field strength can be increased. Another major advantage of non-aqueous media is the good solubility of less-polar compounds, for example, long-chained fatty acids [46]. According to Porras and Kenndler, the often-cited selectivity and efficiency improvements for CE analyses in nonaqueous media are based on heteroconjugation and/or ion pairing rather than on selective changes of the analyte mobilities or $\mathrm{p} K_{\mathrm{a}}$ values [45]. As most buffer salts used for CE separations are not fairly soluble in non-aqueous media, the use of electrolytes in NACE is often restricted to ammonium acetate and ammonium formate, which also allows the application of these buffer systems for CE/MS analyses. In fact, one major reason for the popularity of non-aqueous running buffers is their applicability for CE/ MS [47]. The high amount of organic solvents in non-aqueous 
Table 1 Selected examples for the analysis of secondary plant metabolites with NACE.

\begin{tabular}{|c|c|c|c|}
\hline Natural product class & Plant species & Electrolyte & Ref. \\
\hline Alkaloids & - & $50 \mathrm{mM}$ ammonium acetate, $0.6 \mathrm{M} \mathrm{AcOH}$ in MeOH-ACN $(75: 25, \mathrm{v} / \mathrm{v})$ & [48] \\
\hline Anthraquinones & Xanthophytum attopvensis & 50 mM sodium cholate, $1.0 \%(v / v) \mathrm{AcOH}, 40 \%(\mathrm{v} / \mathrm{v}) \mathrm{ACN}$ in $\mathrm{MeOH}$ & [51] \\
\hline Coumarins & Cortex Fraxini, Fraxinus spp. & $\begin{array}{l}60 \mathrm{mM} \text { sodium cholate, } 20 \mathrm{mM} \text { ammonium acetate, } 3.0 \%(\mathrm{v} / \mathrm{v}) \mathrm{AcOH}, 20 \%(\mathrm{v} / \mathrm{v}) \\
\text { ACN in MeOH }\end{array}$ & [52] \\
\hline Flavones & Chinese herbs & $10 \mathrm{mM}$ sodium cholate, $80 \mathrm{mM}$ TRIS in ACN-MeOH (60:40, v/v) & [53] \\
\hline Diterpenes & Danshen (Salvia miltiorrhiza) & $250 \mathrm{mM}$ ammonium acetate, $1.0 \%(\mathrm{v} / \mathrm{v}) \mathrm{AcOH}, 30 \%(\mathrm{v} / \mathrm{v}) \mathrm{ACN}$ in $\mathrm{MeOH}$ & [55] \\
\hline Hypericins and hyperforins & $\begin{array}{l}\text { St. John's wort } \\
\text { (Hypericum perforatum) }\end{array}$ & $\begin{array}{l}50 \mathrm{mM} \text { ammonium acetate, } 150 \mathrm{mM} \text { sodium acetate, } 0.002 \%(\mathrm{w} / \mathrm{v}) \text { hexadi- } \\
\text { methrine bromide in } \mathrm{MeOH}-\mathrm{DMSO}-\mathrm{N} \text {-methylformamide }(3: 2: 1, \mathrm{v} / \mathrm{v} / \mathrm{v})\end{array}$ & [57] \\
\hline
\end{tabular}

buffers increases their volatility and strongly reduces the surface tension of the droplets generated via electrospray ionisation (ESI). Therefore, non-aqueous media often provide a higher sensitivity and compatibility for CE/ESI-MS compared with aqueous electrolytes. Natural products analysed with NACE include alkaloids [48-50], anthraquinones [51], coumarins [52], flavonoids [53], polyphenolic compounds [54], terpenes [55, 56], and hypericins and hyperforins from Hypericum perforatum [57]. Additional references are listed in the recently published reviews of Scriba [47] and Geiser and Veuthey [58]. Selected examples for NACE separations of natural products are given in Table 1.

\section{Electrokinetic Chromatography}

$\nabla$

Neutral substances without acidic or basic functional groups and which cannot be transferred to charged complexes can be analysed with electrokinetic chromatography (EKC). In contrast to CZE, electrokinetic separation techniques (e.g., micellar electrokinetic chromatography [MEKC], microemulsion electrokinetic chromatography [MEEKC], and capillary electrochromatography [CEC]) are based on the distribution of analytes between a stationary or pseudo-stationary phase and the mobile phase driven by the EOF. In the following paragraphs the characteristics of these methods and their potential for natural products analysis will be explained.

\section{Micellar electrokinetic chromatography}

MEKC was introduced by Terabe and coworkers in 1984 [59] and rapidly proved to be the method of choice for the $\mathrm{CE}$ analysis of neutral compounds. In MEKC, a pseudo-stationary phase is generated by the addition of a micelle-forming ionic surfactant molecule such as sodium dodecyl sulphate (SDS) or cetyltrimethylammonium bromide. Above the critical micelle concentration, the tenside molecules aggregate to micelles where the polar and water-soluble "head" of the surfactant molecules constitutes the outer surface and the hydrophobic part of the molecule forms a lipophilic core. Whereas the selectivity of CZE separations is based on different electrophoretic mobilities of the analyte ions, the separation mechanism in MEKC is based on hydrophobic interactions of the sample molecules with the applied pseudo-stationary phase and - if the analytes are charged at the $\mathrm{pH}$ value of the buffer - different electrophoretic mobilities. In the case of charged compounds, the overlap of the two separation mechanisms (hydrophobic interaction and electrophoretic mobility) can lead to a significant gain in selectivity; therefore, MEKC has been frequently applied for challenging separations of natural products in crude plant extracts and pharmaceutical formulations [10-12]. Because crude plant extracts contain a variety of acidic, basic, and neutral compounds, MEKC is of particular interest for the simultaneous analysis of charged and uncharged substances in crude plant extracts (e.g., for fingerprint analyses) [10$12,60]$. For example, Ganzera et al. recently reported the successful MEKC separation of phenolic acids and flavonoids from Arnica montana [60]. Kaempferol 3-O-glucoside (1), 6-methoxy-kaempferol 3-O-glucoside (2), hispidulin (3), quercetin 3-O-glucoside (4), patuletin 3-O-glucoside (5), quercetin 3-O-glucuronic acid (6), chlorogenic acid (7), 3,5-dicaffeoylquinic acid (8), and 4,5-dicaffeoylquinic acid (9) were separated using an electrolyte consisting of $50 \mathrm{mM}$ borate (pH6.75), $25 \mathrm{mM}$ SDS, and 30\% (v/v) ACN (๑ Fig. 1) [60]. The crude plant extracts were hydrodynamically injected ( $50 \mathrm{mbar}$ for $5 \mathrm{~s}$ ) into the fused silica capillary $(62 \mathrm{~cm} \times 50 \mu \mathrm{m}$ i.d.), and the separation voltage and capillary temperature were $25 \mathrm{kV}$ and $40^{\circ} \mathrm{C}$, respectively. As can be clearly seen in 1 Fig. 1, the analytes migrated in two distinct groups according to their $\mathrm{p} K_{\mathrm{a}}$ values. At a $\mathrm{pH}$ value of 6.75 , the dissociation of hispidulin (3) and the flavonoid glycosides 1, 2, 4, and 5 is negligible, so that the migration velocity of these compounds is predominantly determined by their affinity to the pseudo-stationary phase (SDS) and the formation of complexes with borate anions. For quercetin 3-O-glucuronic acid (6) and the phenolic acids (7-9), however, the longer migration times are due to the almost complete dissociation of their carboxylic groups. This deprotonation leads to a strong electrophoretic mobility to the anode but also to a reduced incorporation into the SDS micelles because of repulsion forces and higher polarity.

In addition to the above-mentioned example, MEKC has been frequently applied for the analysis of natural products, for example, alkaloids [61-63], anthraquinones [64,65], cardiac glycosides [66], catechins [67,68], coumarins [69], ecdysones [70], flavonoids [71-73], glucosinolates [74,75], isoflavones [76,77], procyanidins [78,79], saponins [80], and terpenes [81,82]. Examples for MEKC separations of secondary plant metabolites are given in - Table 2.

\section{Microemulsion electrokinetic chromatography}

In recent years microemulsion electrokinetic chromatography (MEEKC) has become an attractive alternative to previously established CE methods such as CZE and particularly MEKC [83]. An important prerequisite for the performance of MEEKC analyses with UV detection is the use of running buffers with optically transparent emulsions containing oil droplets below $10 \mathrm{~nm}$ so that light scattering does not occur. Such microemulsions are obtained by dispersion of immiscible liquids in an aqueous buffer in the presence of surfactants that decrease the surface tension between the two liquid layers. The addition of a short-chain alcohol such as butanol (co-surfactant) further lowers the droplet's surface tension. Whereas the oil phase typically consists of heptane 


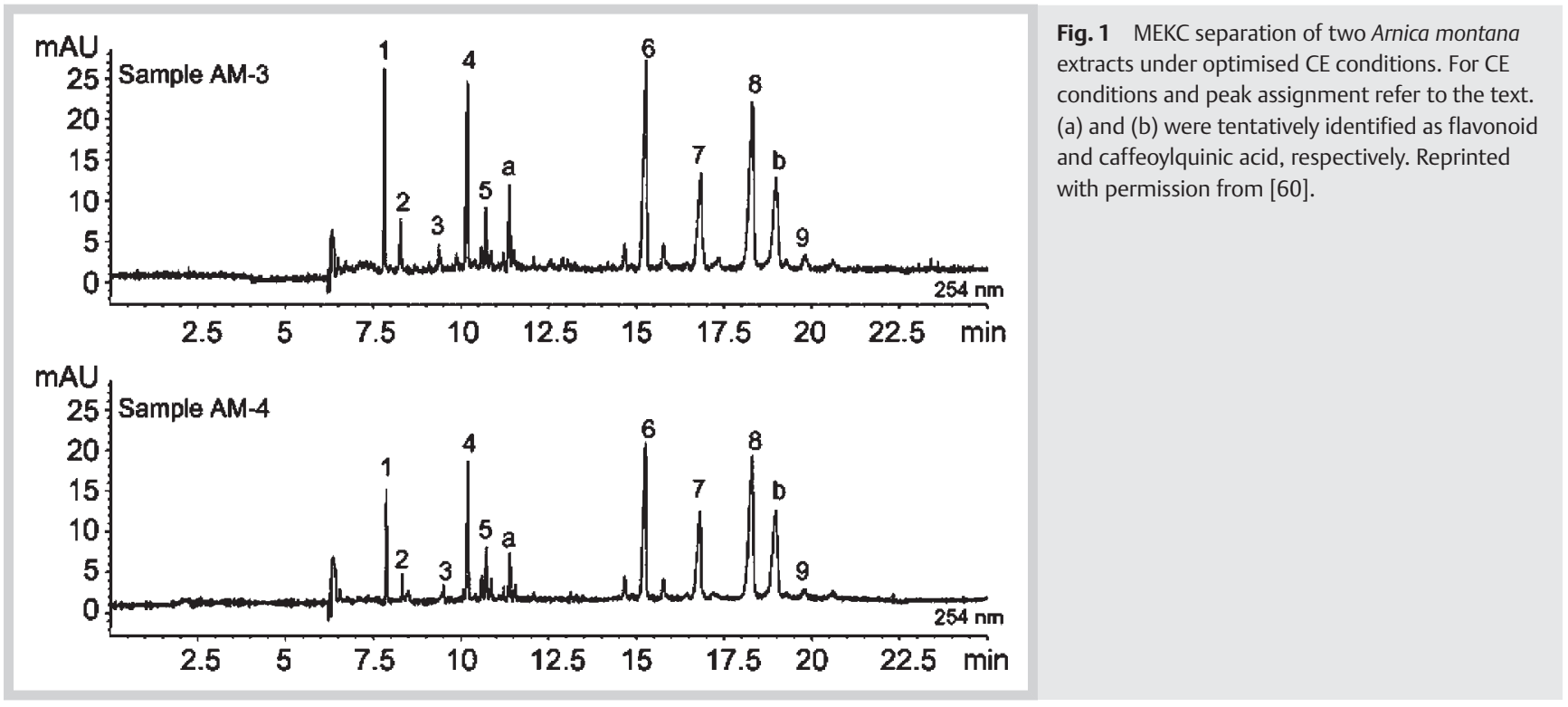

Table 2 Selected examples for the analysis of natural products with MEKC.

\begin{tabular}{ll} 
Natural product class & Plant species \\
\hline Tropane alkaloids & Hyoscyamus muticus \\
\hline Anthraquinones & Rhubarb (Rheum rhaponticum) \\
\hline Catechins & Green tea (Camellia sinensis) \\
\hline Ecdysteroids and flavonoids & Serratula strangulata \\
\hline Flavonoids & Ixeridium gracile \\
\hline Flavonoids & Astragalus membranaceus \\
\hline Isoflavones & Medicago spp., Melilotus alba \\
Flavonoids and terpene & Ginkgo biloba
\end{tabular}

lactones

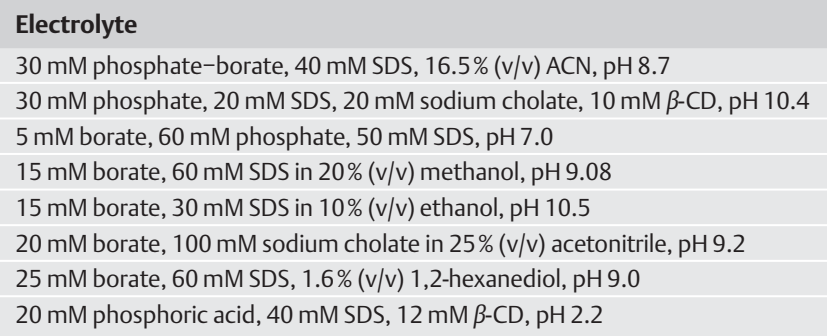

Ref. or octane, the aqueous phase comprises borate, phosphate, or TRIS buffers at basic pH values between 7 and 11; however, MEEKC analyses at low buffer $\mathrm{pH}$ values also have been reported $[84,85]$. Although most MEEKC applications use oil-in-water emulsions, the use of reverse MEEKC with water-in-oil emulsions is also possible and is particularly advantageous for the separation of highly hydrophobic compounds [86]. Comparable to MEKC, enantioselective microemulsions that contain chiral surfactants or chiral alcohols allow the enantioseparation of analytes in racemic mixtures. For example, Aiken and Huie described a novel chiral microemulsion based on $(2 R, 3 R)$-di-n-butyl tartrate $(0.5 \% \mathrm{w} / \mathrm{w})$ as a water-immiscible chiral selector [87]. The addition of this chiral selector to the running buffer consisting of $0.6 \%(\mathrm{w} / \mathrm{w})$ SDS and $1.2 \%(\mathrm{w} / \mathrm{w})$ butanol in $15 \mathrm{mM}$ TRIS ( $\mathrm{pH} 8.1$ ) allowed the enantiomeric separation of a racemic mixture of ephedrine (selectivity factor: 2.6) [87]. Especially because of its applicability for charged, neutral, and lipophilic compounds, MEEKC is an interesting alternative for the analysis of secondary plant metabolites complimentary to CEC, MEKC, and RP-HPLC [83].

An impressive example of the MEEKC analysis of lipophilic and medium polar plant constituents has been published by Vanhoenacker et al., who separated the rather unstable hop ingredients humulone, adhumulone, and cohumulone ( $\alpha$-acids) and lupulone, adlupulone, and colupulone ( $\beta$-acids) as well as the chalcone derivatives isoxanthohumol, 6-prenylnaringenin, and 8- prenylnaringenin [86]. The separation was obtained using a running buffer containing $10 \mathrm{mM}$ borate adjusted to a $\mathrm{pH}$ value of 9.7, $40 \mathrm{mM}$ SDS, 3\% (v/v) butanol, and $0.3 \%(\mathrm{v} / \mathrm{v})$ heptane. Injections were performed hydrodynamically for $3 \mathrm{~s}$ at $50 \mathrm{mbar}$, and between two runs the capillary was rinsed sequentially for $1.5 \mathrm{~min}$ with $50 \mathrm{mM}$ borate and then with the separation buffer. The temperature of the capillary was set to $25^{\circ} \mathrm{C}$ and the applied separation voltage was $30 \mathrm{kV}$ [86]. The $\mathrm{pH}$ value was an extremely important experimental condition, whereas an increase in the SDS concentration or the replacement of butanol by pentanol did not significantly affect the separation. By using the abovementioned conditions, a baseline separation of the applied hop constituents could be obtained, and it was also possible to detect these compounds in hop extracts [86]. Other natural products that have been analysed with MEEKC include anthraquinones and bianthrones in rhubarb [88], catechins in green and black tea [84,85], ephedrine alkaloids in Chinese herbs [89], sesquiterpene lactones of radix inulae (Inula helenium) [90], and xanthones from Securidaca inappendiculata [91]. The buffer systems used for these MEEKC separations are given in $\bullet$ Table 3.

\section{Capillary electrochromatography}

Capillary electrochromatography (CEC) can be addressed as a hybrid-technique that combines chromatography with capillary electrophoresis. In CEC the mobile phase is normally driven through the stationary phase by the EOF. In contrast to MEKC 
Table 3 Selected examples for the analysis of secondary plant metabolites with MEEKC.

\begin{tabular}{|c|c|c|c|}
\hline Natural product class & Plant species & Electrolyte & Ref. \\
\hline Anthraquinones & $\begin{array}{l}\text { Rhubarb } \\
\text { (Rheum rhaponticum) }\end{array}$ & $\begin{array}{l}97.7 \%(\mathrm{w} / \mathrm{v}) 10 \mathrm{mM} \text { sodium borate }(\mathrm{pH} 9.2), 0.6 \%(\mathrm{w} / \mathrm{v}) \mathrm{SDS}, 0.5 \%(\mathrm{w} / \mathrm{v}) \text { dibutyl-L- } \\
\text { tartrate, } 1.2 \%(\mathrm{w} / \mathrm{v}) \text { butanol, } 0-40 \%(\mathrm{w} / \mathrm{v}) \text { ACN }\end{array}$ & [88] \\
\hline Catechins & $\begin{array}{l}\text { Green tea } \\
\text { (Camellia sinensis) }\end{array}$ & $\begin{array}{l}86.61-94.13 \%(\mathrm{w} / \mathrm{v}) 50 \mathrm{mM} \text { phosphate }(\mathrm{pH} 2.5), 2.31-3.32 \%(\mathrm{w} / \mathrm{v}) \mathrm{SDS}, 1.36 \%(\mathrm{w} / \mathrm{v}) \\
\text { heptane, } 7.58-9.72 \%(\mathrm{w} / \mathrm{v}) \text { co-surfactant }\end{array}$ & [84] \\
\hline Ephedrine alkaloids & Chinese herbs & $\begin{array}{l}20 \mathrm{mM} \text { borate, } 23.3 \mathrm{mM} \text { SDS, } 16.4 \mathrm{mM} \text { heptane, } 180.85 \mathrm{mM} \text { butanol in } 8 \% \mathrm{ACN} \text {, } \\
\mathrm{pH} 9.4\end{array}$ & [89] \\
\hline Phenolic acids and catechins & $\begin{array}{l}\text { Black tea } \\
\text { (Camellia sinensis) }\end{array}$ & $\begin{array}{l}86.1 \%(\mathrm{v} / \mathrm{v}) 25 \mathrm{mM} \text { phosphate }(\mathrm{pH} 2.0), 2.89 \%(\mathrm{w} / \mathrm{v}) \mathrm{SDS}, 1.36 \%(\mathrm{w} / \mathrm{v}) \text { heptane, } \\
7.66 \%(\mathrm{w} / \mathrm{v}) \text { cyclohexanol, } 2 \%(\mathrm{w} / \mathrm{v}) \text { ACN }\end{array}$ & [85] \\
\hline Sesquiterpene lactones & $\begin{array}{l}\text { Radix Inulae } \\
\text { (Inula helenium) }\end{array}$ & $\begin{array}{l}85.8 \%(\mathrm{w} / \mathrm{v}) \text { sodium tetraborate, } 1.24 \%(\mathrm{w} / \mathrm{v}) \mathrm{SDS}, 0.32 \%(\mathrm{v} / \mathrm{v}) \text { hexane, } 2.64 \%(\mathrm{v} / \mathrm{v}) \\
\text { butanol, } 10 \%(\mathrm{v} / \mathrm{v}) \text { ACN, pH } 9.2\end{array}$ & [90] \\
\hline Xanthones & Securidaca inappendiculata & $\begin{array}{l}50 \mathrm{mM} \text { borate, } 120 \mathrm{mM} \text { SDS, } 80 \mathrm{mM} \text { heptane, } 10 \%(\mathrm{v} / \mathrm{v}) \text { butanol, } 5 \mathrm{mM} \text { sulphated } \beta \text { - } \\
\text { CD, pH } 9.5\end{array}$ & [91] \\
\hline
\end{tabular}

Table 4 Selected examples for the analysis of secondary plant metabolites with CEC.

\begin{tabular}{ll} 
Substance class & Stationary phase \\
\hline Purine alkaloids & Silica; $3 \mu \mathrm{m}$ \\
\hline Anthraquinones & Hypersil $\mathrm{C}_{18} ; 3 \mu \mathrm{m}$ \\
\hline Boswellic acids & Hypersil $\mathrm{C}_{18} ; 3 \mu \mathrm{m}$ \\
\hline Cannabinoids & Hypersil $\mathrm{C}_{8 / 18} ; 3 \mu \mathrm{m}$ \\
\hline Flavanones & Lichrospher $\mathrm{C}_{18} ; 5 \mu \mathrm{m}$ \\
\hline Isoflavones & Monolith \\
\hline Plant sterols & Hypersil $\mathrm{C}_{18} ; 3 \mu \mathrm{m}$ \\
\hline Withanolides & Hypersil $\mathrm{C}_{18} ; 3 \mu \mathrm{m}$
\end{tabular}

and MEEKC, the analyses are performed in coated, packed, or monolithic capillaries. There are three common types of stationary phases applied in CEC: (i) capillary columns with packed homogenous silica or reversed-phase silica particles with a diameter of about $3 \mu \mathrm{m}$; (ii) capillaries coated with the stationary phase; or (iii) monolithic capillary columns made by an in situ polymerisation of suitable polymer materials inside the capillary. Whereas for neutral compounds the separation mechanism is primarily based on interactions of the analytes with the applied stationary phase, charged compounds are separated because of their electrophoretic mobility and their affinity to the stationary phase. As for MEKC and MEEKC, this aspect is favourable for fingerprint analyses of crude plant extracts and often reveals excellent selectivities for complex separations. For the most often used reversed-phase stationary phases in CEC, the mobile phase typically consists of a mixture of organic solvents with buffers (e.g., phosphate or borate) [92]. Comparable to NACE and MEEKC, the use of mobile phases with high contents of organic solvents allows the separation of lipophilic natural products (e.g., boswellic acids, cannabinoids, or tocopherols) (@ Table 4). This aspect contributed to the use of CEC and CEC/MS for the analytical characterisation of plant extracts [92]. Because a detailed overview of the application of CEC for the analysis of natural products was recently given by Scherz et al. [92], single applications will not be presented at this point. Instead, selected examples for the application of CEC in natural products analysis and the corresponding references are given in $\mathbf{O}$ Table 4.

\begin{tabular}{|c|c|}
\hline Mobile phase & Ref. \\
\hline IsoOH, hexane, 1 mM TRIS (pH 8.0) 52:40:8 & [93] \\
\hline $5 \mathrm{mM} \mathrm{AcOH}-\mathrm{ACN} 20: 80$ & [94] \\
\hline $20 \mathrm{mM}$ ammonium formate (pH 6.5), ACN $1: 9$ (v/v) & [95] \\
\hline ACN, 25 mM phosphate (pH 2.57), $75: 25$ & [96] \\
\hline $2.5 \mathrm{mM}$ ammonium formate-ACN $80: 20$ & [97] \\
\hline $2.4 \mathrm{mM}$ ammonium formate ( $\mathrm{pH} 2.7$ ), ACN 70:30 & [98] \\
\hline ACN, THF, 25 mM TRIS (pH 8.0) 60:35:5 & [99] \\
\hline $10 \mathrm{mM}$ ammonium acetate ( $\mathrm{pH} 8.0$ ), ACN 40:60 & [100] \\
\hline
\end{tabular}

\section{CE vs. HPLC in the Analysis of Natural Products} $\nabla$

Although the performance of $\mathrm{CE}$ instruments and the handling of the capillaries have been improved in recent years, there are still some difficulties such as capillary conditioning, capillary cleaning, and blockage of the capillary due to particles or precipitation of buffer components. Especially the cleaning procedures between runs have to be carefully evaluated and validated, because they have a strong impact on the reproducibility of migration times and peak areas in fused silica capillaries [101]. For example, alkaloids tend to strongly adsorb to the capillary wall, which results in distorted peak shapes or sometimes a complete loss of the signal [18]. Although the use of running buffers with ammonium ions (e.g., ammonium acetate) reduces the adsorption of basic analytes to the capillary wall, exact cleaning procedures with water, sodium hydroxide, or even SDS [102] as well as a sufficient re-equilibration with the electrolyte are essential for reproducible results [101]. Because these cleaning procedures often last several minutes, cleaning and re-equilibration of the inner capillary surface often exceeds the analysis time. Whereas reproducibility, handling, and robustness are major advantages of conventional reversed-phase HPLC (RP-HPLC), the high separation efficiency and selectivity as well as short analysis times are favourable attributes of CE. However, short analysis times and high separation efficiencies were recently achieved for HPLC by the introduction of short HPLC columns with small diameters and particle sizes below $3 \mu \mathrm{m}$. This technical progress led to the development of ultrahigh-pressure liquid chromatography, which was recently reviewed by Wu and Clausen [103]. Perhaps one of the most striking drawbacks of HPLC compared with CE is the limited applicability of normal-phase and RP-HPLC methods for the analysis of highly polar compounds such as phenolic 
acids/glycosides, glucuronide and sulphate conjugates, purine and pyrimidine bases, nucleotides, and water-soluble vitamins. These polar compounds are normally not soluble in the nonaqueous solvents used for normal-phase chromatography, and they do not show a sufficient affinity to the most often applied reversed-phase silica gel. Furthermore, the application of aminoalkyl- or diol-based silica columns often does not provide reproducible results or sufficient robustness. Although the introduction of hydrophilic interaction chromatography was an important development for HPLC analysis of polar compounds with acetonitrile-water mixtures containing varying contents of alcohols and electrolytes [104], the analysis of highly water-soluble natural products with HPLC is still a challenge. For CE, however, the analysis of polar substances can be easily done with various methods (e.g., CZE, MEKC, or even NACE). For example, highly polar calystegines could be easily determined both qualitatively and quantitatively with CZE [105], whereas, in this case, the application of RP-HPLC was not possible. Another example is the use of CZE for the quantification of resveratrol in a food supplement in the presence of acesulfame $\mathrm{K}$, riboflavin, ascorbic acid, flavanones, and hydroxycinnamic acids [106]. By using a running buffer consisting of $23 \mathrm{mM}$ borate ( $\mathrm{pH} 10.0)$ with $7 \%(\mathrm{v} / \mathrm{v}$ ) acetonitrile, a baseline separation of all components was obtained in only seven minutes.

Its limited robustness and sometimes difficult manageability has hampered the establishment of $\mathrm{CE}$, and especially $\mathrm{CE} / \mathrm{MS}$, in research facilities and quality-control laboratories. But, as outlined in the next section, the number of CE/MS applications has steadily increased as the demand for rapid, efficient, and multidimensional analytical methods increases.

\section{Capillary Electrophoresis-Mass Spectrometry}

$\nabla$

Since its introduction in 1987 by Olivares et al. [107], CE/MS has evolved to a widely applicable, multidimensional analytical technique complementary to conventional LC/MS methods. One of the major problems that had to be solved for the application of CE/MS was the extremely small liquid flow inside the CE capillaries, which normally ranges from a few nanoliters to several hundred nanoliters per minute. Because even the typical flow rates of microscale LC/MS systems are in the low $\mu \mathrm{L} / \mathrm{min}$ range, the flow-out of the CE capillary has to be increased. For this purpose, a so-called make-up flow (ca. $1-5 \mu \mathrm{L} / \mathrm{min}$ ) is added to the capillary flow via a simple tee (liquid junction) or as a coaxial sheath liquid (sheath flow). Although other online interfaces (e. g., sheathless, direct electrode) have been developed, nowadays almost all CE/MS applications use the sheath-flow interface introduced by Smith and coworkers in 1988 [108]. Whereas the sheath-liquid reduces the sensitivity due to additional background noise and the additional solvent, this approach also allows the post-column addition of chemicals in order to improve ESI characteristics and ionisation efficiency. This is particularly relevant if buffer additives with a low volatility or ion-pairing reagents must be used [109].

CE/MS analyses of natural products were first published in 1994 by Hsieh et al. for the qualitative analysis of the protoberberine alkaloids berberine and palmatine [110] and again in 1994 by Henion et al. for the quantitative determination of isoquinoline alkaloids in the bark of Phellodendron wilsonii [111]. Both groups used tandem MS and a sheath-flow interface instead of a liquidjunction interface to obtain a stable electrospray. In 1997, a gen- erally applicable buffer system for the CZE and CE/MS analysis of various alkaloid classes was developed by Unger et al. [16]. A $1: 1$ mixture of $100 \mathrm{mM}$ ammonium acetate, adjusted to $\mathrm{pH} 3.1$, and acetonitrile allowed the CZE separation of monoterpenoid indole alkaloids, isoquinoline alkaloids, $\beta$-carboline, and opium alkaloids. By reducing the ammonium acetate concentration to $80 \mathrm{mM}$ and adjusting the $\mathrm{pH}$ value to 4.0 before the solution was mixed with acetonitrile, the electrolyte was also suitable for the $\mathrm{CE} / \mathrm{MS}$ analysis of the aforementioned alkaloid classes in crude extracts from opium and the cortex of Aspidosperma quebrachoblanco and from root and cell suspension cultures of Rauwolfia serpentina [112,113]. Isoquinoline alkaloids were also analysed by Sturm et al., who applied a running buffer consisting of ammonium formate (70 or $100 \mathrm{mM}$ ), adjusted to $\mathrm{pH} 3.0$ or 4.0 , and methanol or acetonitrile as buffer additives [17]. By using a sheathflow ( $5 \mathrm{mM}$ formic acid in acetonitrile) at a flow rate of $3 \mu \mathrm{L} / \mathrm{min}$ and ESI in the positive mode, they obtained $[\mathrm{M}]^{+}$ions in the case of quaternary isoquinoline alkaloids such as berberine or sanguinarine and $[\mathrm{M}+\mathrm{H}]^{+}$ions for the tertiary amines (e.g., chelidonine). This method was successfully applied for the analytical characterisation of the alkaloid pattern in crude methanolic extracts of Berberis vulgaris, Chelidonium majus, Eschscholzia californica, Jateorhiza palmata, and Hydrastis canadensis [17]. Approximately 10 years later again Stuppner and coworkers applied CE/MS for the analysis of isoquinoline alkaloids [114]. In this case NACE and ion-trap tandem MS with a sheath-flow ESI interface was used for the analysis of isoquinoline alkaloids in central European Corydalis species. The non-aqueous electrolyte used for the NACE/ESI-/MS analysis was a mixture of $50 \mathrm{mM}$ ammonium acetate, $1 \mathrm{M}$ acetic acid, and $10 \%(\mathrm{v} / \mathrm{v})$ methanol in acetonitrile [114]. Among the alkaloid classes also analysed with CE/ MS are glycoalkaloids from Solanum tuberosum [115], naphthylisoquinoline alkaloids from a Central African Ancistrocladus species [116], quinolizidine alkaloids from Sophora flavescens [117], and tropane alkaloids from Atropa belladonna [118].

Naturally, the application of CE/MS is not restricted to alkaloids. Since 1997 almost all classes of natural products have been analysed with CE coupled to various types of MS instruments $[6,8$, $15,36,92,119,120]$. Both ion-trap and time-of-flight (TOF) MS have been applied for the CE/MS analysis of intact glucosinolates in Arabidopsis thaliana [36]. Due to the very low and almost identical $\mathrm{p} K_{\mathrm{a}}$ values of the permanently charged sulphate groups of the intact glucosinolates, CZE analysis of these compounds at a $\mathrm{pH}$ value near the $\mathrm{p} K_{\mathrm{a}}$ values of the analytes - which normally provides the optimum selectivity - was not possible. Furthermore, because glucosinolates form relatively stable ion pairs with ammonium ions, thereby reducing the sensitivity for MS detection, the use of ammonium acetate or formate for the running buffer and sheath liquid was avoided. By using $1 \mathrm{M}$ and $0.2 \%(\mathrm{~m} /$ $v$ ) formic acid as electrolyte and sheath liquid, respectively, the glucosinolates could be successfully identified with CE/MS in crude extracts without interference from ubiquitous acidic plant constituents such as benzoic or cinnamic acids, which possess much higher $\mathrm{p} K_{\mathrm{a}}$ values and thus are not negatively charged under the applied conditions. The intact glucosinolates, however, maintained their electrophoretic mobility even under the acidic conditions of the applied electrolyte ( $1 \mathrm{M}$ formic acid) and migrated as anions, which are easily detectable with ESI in the negative-ion mode [36]. In $\odot$ Fig. 2, the CE/ESI-TOF-MS base peak electropherogram of the glucosinolate pattern of a crude Arabidopsis thaliana extract is shown. The application of CE/TOF-MS finally allowed the assignment of glucosinolates that could not be 


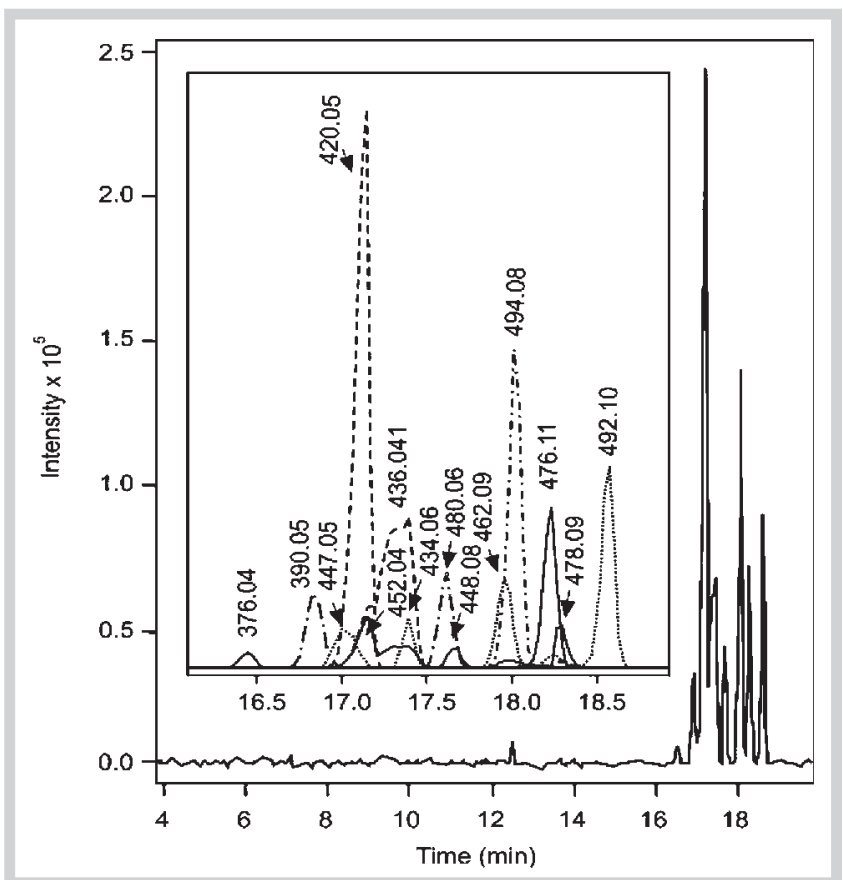

Fig. 2 Base peak electropherogram as obtained by CE/ESI-TOF-MS of a crude Arabidopsis thaliana seed extract. The insert shows a detailed view of extracted ion electropherograms ( $\mathrm{m} / \mathrm{z}$ values) of the major compounds. Reprinted with permission from [36]

identified with ion-trap MS. However, as stated by the authors, even with TOF-MS it was not possible to unequivocally identify all peaks according to their elemental composition because of overlapping isotopic patterns of co-eluting compounds [36].

\section{CE|MS vs. LC|MS in the Analysis of Natural Products $\nabla$}

A direct comparison of the applicability of CE/MS and LC/MS for the analysis of natural products was published by Vanhoenacker et al., who analysed phenolic compounds in diethyl ether extracts of red wines [120]. For these analyses both CE/MS and LC/MS were performed with ESI in the negative-ion mode. Despite the higher separation efficiency of CE compared with HPLC, the application of LC/MS in this case was superior because better selectivity and sensitivity were obtained. Moreover, by applying a single-quadrupole mass spectrometer, 23 red wine constituents could be identified using LC/MS, whereas only 13 ingredients could be identified with CE/MS. Interestingly, the application of a more volatile ammonium acetate buffer ( $25 \mathrm{mM}, \mathrm{pH} 9.5)$ instead of an ammonium borate buffer ( $18.75 \mathrm{mM}$, pH 9.3) during $\mathrm{CE} / \mathrm{MS}$ did not result in better sensitivity or improved peak identification. The sensitivity was increased for the catechins and the phenolic acids, but the separation and the signal intensities of the flavonols decreased [120]. The main reason for this result was the significant loss in separation selectivity when borate was replaced by acetate. Obviously, the complexation of aromatic or cis-configured vicinal hydroxy groups by borate anions was the key to the successful separation of the flavonols. This complexation also influenced the ionisation behaviour and fragmentation of the phenolic compounds, because the red wine constituents with a vicinal hydroxy group preferentially showed cluster ions with borate or borate and methanol from the sheath liquid [120]. However, it should be mentioned that for CE/MS analyses the application of single-quadrupole mass spectrometers is particularly unfavourable for fingerprint analyses of natural products because these instruments show a relatively low sensitivity in scan mode. That is why most of the CE/MS analyses of crude plant extracts have been performed with ion-trap MS, which provides a much higher sensitivity in scan mode.

\section{Online Pre-Concentration Methods \\ $\nabla$}

Whereas in CE very low absolute sample amounts, typically in the low picogram range, are detected, the low injection volumes and the narrow diameter of the capillaries typically used (25$100 \mu \mathrm{m}$ ) lead to a poor concentration sensitivity for the most often applied UV detection. For molecules with average extinction coefficients, such as flavones, the limit of detection often lies between 1 and $10 \mu \mathrm{g} / \mathrm{mL}$. Even for CE coupled to MS, the concentration sensitivity is only somewhat higher compared with $\mathrm{CE}$ with UV detection because the sheath liquid necessary to obtain a stable nanospray dilutes the sample and causes additional background noise [109]. To overcome the low concentration sensitivity of CE analyses, several strategies are currently applied. These strategies involve the use of capillaries with extended detection path lengths (e.g., Z-shaped, multi-reflection, bubble cell) or the application of highly sensitive detection methods such as electrochemical or fluorometric detection. The combination of an extended detection path length with laser-induced fluorescence (LIF) was reported recently for the sensitive detection of riboflavin and other aromatic compounds [121]. Because the laser intensity had to be decreased when bubble cells were used, the sensitivity for riboflavin, for example, was only 8 times higher compared with conventional UV detection [121]. Nevertheless, the use of LIF detectors generally results in a significant increase in sensitivity if the target analytes possess a fluorophoric structure. Although one major drawback is the limited availability of excitation and emission wavelengths for LIF detectors, this technique has been applied several times in the past for the CE analysis of natural products [122-124]. Comparable to catecholamines, many flavonoids can be electrochemically detected with high sensitivity because the catechol structures of, e.g., quercetin or luteolin can be easily oxidised to ortho-quinones. Thus, electrochemical detection was preferentially applied for the CE analysis of flavonoids $[125,126]$.

An alternative strategy to the use of extended detection path lengths or more sensitive detection methods is the application of online pre-concentration methods such as stacking or sweeping. For a comprehensive overview of these methods, refer to the excellent review of Simpson et al. [127]. Originally applied for charged compounds in CZE applications, online pre-concentration techniques are nowadays also widely used for the MEKC or MEEKC analysis of natural products $[128,129]$. During online pre-concentration a relatively large sample amount is introduced into the CE capillary with hydrodynamic or electrokinetic injection, and the target analytes are focused in a narrow band before the separation begins. The focusing of sample molecules most often results from (i) a different field strength in the sample zone and running buffer (e.g., stacking, field-enhanced sample stacking, FESS); (ii) a change in the effective charge of the analyte (e.g., dynamic pH junction); or (iii) the partitioning of the sample molecules in a pseudo-stationary phase such as SDS (sweeping). 
The application of these online pre-concentration techniques provides a 10 - to 1000 -fold enhancement in concentration sensitivity, or even higher if large sample amounts can be introduced into the capillary [127]. The first application of a simple and effective online pre-concentration method for the $\mathrm{CE}$ analysis of natural products in crude plant extracts was published by Unger and Stöckigt in 1997 [130]. They used field-amplified sample injection (FASI) for the determination of alkaloids in crude methanolic extracts from the roots of Berberis vulgaris and Hydrastis canadensis. By introducing a short plug of methanol $70 \%(\mathrm{v} / \mathrm{v})$ before electrokinetic injection of the alkaloids at $16 \mathrm{kV}$ for $8 \mathrm{~s}$, the concentration sensitivity was 1000 times higher compared with hydrodynamic injection at 345 mbar for $1 \mathrm{~s}$ [130].

The online enrichment of charged substances with FASI is not limited to CZE separations and can be combined with other CE separation methods such as MEEKC. The combination of FASI with MEEKC was used by Yu et al. to analyse trace amounts of the quinolizidine alkaloids sophoridine, matrine, oxymatrine, oxysophocarpine, and cytisine in the roots of Sophora flavescens [129]. In this case the obtained LODs (defined as signal-to-noise ratio $=3$ ) for the analytes were as low as $0.1 \mathrm{ng} / \mathrm{mL}$, which is approximately 10000 times higher compared with conventional hydrodynamic injection.

Among the various online pre-concentration methods, FESS, FA$\mathrm{SI}$, dynamic pH junction, and sweeping can be considered the most useful techniques for the analysis of trace amounts of natural products in crude plant extracts, pharmaceutical formulations, and even body fluids such as urine or plasma [127]. For example, a combination of electrokinetic injection, dynamic $\mathrm{pH}$ junction, and sweeping was used for the sensitive determination of sinapic, ferulic, coumarinic, caffeic, syringic, vanillic, and 4-hydroxybenzoic acid in crude acetone extracts from Majorana hortensis [131]. The sample was dissolved in a basic borate buffer ( $50 \mathrm{mM}, \mathrm{pH} 9.5$ ), and both the junction electrolyte and the running buffer (mobilisation electrolyte) consisted of $50 \mathrm{mM}$ phosphate, $\mathrm{pH} 2.5$. The latter also contained $60 \mathrm{mM}$ SDS because the mobilisation and separation of the organic acids were done by reversed-migration MEKC (RM-MEKC). In RM-MEKC the running buffer is adjusted to a low $\mathrm{pH}$ value $(<2.5)$ where virtually no EOF is present or the EOF is suppressed by coating the capillaries [132]. Therefore, the micelles with the partially included analytes migrate to the oppositely charged electrode without being swept by the EOF. For online pre-concentration, the phenolic acids were electrokinetically injected $(-10 \mathrm{kV}, 30 \mathrm{~min})$ from the alkaline sample buffer ( $\mathrm{pH} 9.5$ ) into the junction electrolyte $(\mathrm{pH} 2.5)$; at this point the phenolic acids were neutralised and stacked (accumulation part). After accumulation of the phenolic acids, the sample solution (inlet vial) was replaced by the running buffer (50 mM phosphate, $60 \mathrm{mM}$ SDS, pH 2.5) and the separation voltage $(-10 \mathrm{kV})$ was applied. The negatively charged SDS micelles of the inlet vial migrated to the anode and penetrated the junction electrolyte, where the neutralised phenolic acids were stacked due to the loss in electrophoretic mobility at the acidic $\mathrm{pH}$ value of 2.5. Because of their higher lipophilicity, the neutralised phenolic acids were efficiently incorporated into the SDS micelles and swept to the anode. The obtained LODs between 0.4 and $4.2 \mathrm{ng} / \mathrm{mL}$ mainly resulted from the long duration used for electrokinetic injection (30 $\mathrm{min}$ ) and the stacking process during the accumulation of the negatively charged phenolic acids in the acidic junction electrolyte [131]. However, it can be speculated that the application of a permanently or dynamically coated capillary and a simple electrokinetic injection or FASI at relatively high electrical field strengths may have provided similar results regarding sensitivity enhancement and separation efficiency. Sweeping was originally developed for the online concentration of neutral analytes in MEKC [133]. In this online concentration technique, neutral or charged analytes are picked up and accumulated in micelles of a pseudo-stationary phase that penetrates the sample zone. Because the analytes are incorporated into the micelles, lipophilic molecules are more efficiently concentrated than hydrophilic substances. Also, in order to obtain a strong incorporation of the analytes into the pseudo-stationary phase, buffer additives such as cyclodextrins or organic solvents should be avoided in the sample matrix. In recent years, sweeping has been applied several times for the online pre-concentration of natural products, e.g., alkaloids [134], catechins [135], flavonoids [128], and phenolic acids [136]. By introducing a large sample amount into the capillary via hydrodynamic or electrokinetic injection, sweeping can lead to a dramatic increase in sensitivity (>1000-fold) [127,133]. For example, a 1500-fold improvement in detection sensitivity was obtained by a sweeping technique applied for the MEKC analysis of trans-resveratrol in red wine [137].

\section{Future Perspectives and Concluding Remarks} 7

The ongoing technical advances and future developments in all fields of instrumental analytics will lead to further miniaturisation and improvement of CE instruments. Such improvements may soon lead to the routine $\mathrm{CE}$ analysis of very small absolute sample amounts in the low femtogram range. This sensitivity may be achieved by a combination of various online pre-concentration techniques with highly sensitive detection methods, such as fluorometry or electrochemiluminescence [138].

Because the interest in nanoscale separation techniques is high and still growing, $\mathrm{CE}$ will be the method of choice for future applications in all areas of bioanalytical research. Due to the widespread use of a great variety of medicinal plants for the production of herbal supplements and phytomedical products, one of the future challenges in natural products analysis will be the detection and exact quantification of trace amounts of species-specific constituents (marker compounds) for the unambiguous identification of authentic plant material. Furthermore, CE will be an important tool for the detection and quantification of trace amounts of harmful plant constituents or impurities from toxic plants, for example, aristolochic acids or colchicine. In this regard, it can be speculated that the future application of CE in natural products analysis is directly linked to the availability of robust and highly sensitive detection methods.

\section{Acknowledgements \\ $\nabla$}

The assistance of A. Frank in the preparation of the manuscript is gratefully acknowledged.

\section{References}

1 Mikkers FEP, Everaerts FM, Verheggen ThPEM. High-performance zone electrophoresis. J Chromatogr 1979; 169: 11-20

2 Jorgenson JW, Lukacs $K D$. Zone electrophoresis in open-tubular glass capillaries. Anal Chem 1981; 53: 1298-1302

3 Jorgenson JW, Lukacs KD. Free-zone electrophoresis in glass capillaries. Clin Chem 1981; 27: 1551-1553 
4 Altria $K D$, Elder D. Overview of the status and applications of capillary electrophoresis to the analysis of small molecules. J Chromatogr A 2004; 1023: 1-14

5 Cheung RH, Marriot PJ, Small DM. CE methods applied to the analysis of micronutrients in foods. Electrophoresis 2007; 28: 3390-3413

6 Huck CW, Stecher G, Scherz H, Bonn G. Analysis of drugs, natural and bioactive compounds containing phenolic groups by capillary electrophoresis coupled to mass spectrometry. Electrophoresis 2005; 26 : 1319-1333

7 Kostal V, Katzenmeyer J, Arriaga EA. Capillary electrophoresis in bioanalysis. Anal Chem 2008; 80: 4533-4550

8 Huo Y, Kok WT. Recent applications in CEC. Electrophoresis 2008; 29: 80-93

9 Kraly J, Fazal MA, Schoenherr RM, Bonn R, Harwood MM, Turner E, Jones $M$, Dovichi NJ. Bioanalytical applications of capillary electrophoresis. Anal Chem 2006; 78: 4097-4110

10 Issaq HJ. Capillary electrophoresis of natural products. Electrophoresis 1997; 18: 2438-2452

11 Issaq HJ. Capillary electrophoresis of natural products-II. Electrophoresis 1999; 20: 3190-3202

12 Suntornsuk $L$. Capillary electrophoresis of phytochemical substances. J Pharm Biomed Anal 2002; 27: 679-698

13 Bednár P, Papousková B, Müller L, Barták P, Stávek J, Pavlousek P, Lemr K. Utilization of capillary electrophoresis/mass spectrometry (CE/MSn) for the study of anthocyanin dyes. J Sep Sci 2005; 28: 1291-1299

14 Petersson EV, Puerta A, Bergquist J, Turner C. Analysis of anthocyanins in red onion using capillary electrophoresis-time of flight-mass spectrometry. Electrophoresis 2008; 29: 2723-2730

15 Seguera-Carretero A, Puertas-Mejía MA, Cortacero-Ramírez S, Beltrán $R$, Alonso-Villaverde C, Joven J, Dinelli G, Fernández-Gutiérrez A. Selective extraction, separation, and identification of anthocyanins from Hibiscus sabdariffa L. using solid phase extraction-capillary electrophoresis-mass spectrometry (time-of-flight/ion trap). Electrophoresis 2008; 29: 2852-2861

16 Unger M, Stöckigt D, Belder D, Stöckigt J. General approach for the analysis of various alkaloid classes using capillary electrophoresis and capillary electrophoresis-mass spectrometry. J Chromatogr A 1997; 767: 263-276

17 Sturm S, Stuppner $H$. Analysis of isoquinoline alkaloids in medical plants by capillary electrophoresis-mass spectrometry. Electrophoresis 1998; 19: 3026-3032

18 Unger $M$. Capillary zone electrophoresis of alkaloids - influence of structure on electrophoretic mobility. J Chromatogr A 1998; 807: 8187

19 Lechtenberg M, Quandt B, Nahrstedt A. Quantitative determination of curcuminoids in Curcuma rhizomes and rapid differentation of Curcuma domestica Val. and Curcuma xanthorrhiza Roxb. by capillary electrophoresis. Phytochem Anal 2004; 15: 152-158

20 Honda S, Iwase S, Makino A, Fujiwara S. Simultaneous determination of reducing monosaccharides by capillary zone electrophoresis as the borate complexes of N-2-pyridylglycamines. Anal Biochem 1989; 176: $72-77$

21 Schwaiger H, Oefner PJ, Huber C, Grill E, Bonn GK. Capillary zone electrophoresis and micellar electrokinetic chromatography of 4-aminobenzonitrile carbohydrate derivates. Electrophoresis 1994; 15: 941-952

22 Zong YY, Che CT. Determination of strychnine and brucine by capillary zone electrophoresis. Planta Med 1995; 61: 456-458

23 Eeva M, Salo JP, Oksman-Caldentey KM. Determination of the main tropane alkaloids from transformed Hyoscyamus muticus plants by capillary zone electrophoresis. J Pharm Biomed Anal 1998; 16: 717-722

24 Unger M, Laug S, Holzgrabe U. Capillary zone electrophoresis as a tool for the quality control of goldenseal extracts. Electrophoresis 2005; 26: 2430-2436

25 Koyama J, Morita I, Fujiyoshi H, Kobayashi N. Simultaneous determination of anthraquinones, their 8-beta-D-glucosides, and sennosides of Rhei Rhizoma by capillary electrophoresis. Chem Pharm Bull 2005; 53: 573-575

26 Tian $K$, Zhang $H$, Chen $X, H u$ Z. Determination of five anthraquinones in medicinal plants by capillary zone electrophoresis with beta-cyclodextrin addition. J Chromatogr A 2006; 1123: 134-137

27 Sáenz-López R, Fernández-Zurbano P, Tena MT. Development and validation of a capillary zone electrophoresis method for the quantitative determination of anthocyanins in wine. J Chromatogr A 2003; 990: 247-258
28 Ichiyanagi T, Kashiwada Y, Ikeshiro Y, Hatano Y, Shida Y, Horie Y, Matsugo S, Konishi T. Complete assignment of bilberry (Vaccinium myrtillus L.) anthocyanins separated by capillary zone electrophoresis. Chem Pharm Bull 2004; 51: 226-229

29 Vopli N, Maccari F, Linhardt RJ. Capillary electrophoresis of complex natural polysaccharides. Electrophoresis 2008; 29: 3095-3106

30 Arce L, Rios A, Valcárcel M. Determination of anti-carcinogenic polyphenols present in green tea using capillary electrophoresis coupled to a flow injection system. J Chromatogr A 1998; 827: 113-120

31 Günaydin K, Erim FB. Determination of khellin and visnagin in Ammi visnaga fruits by capillary electrophoresis. J Chromatogr A 2002; 954: 291-294

32 Yue ME, Jiang TF, Liu X, Shi YP. Separation and determination of coumarins from Cacalia tangutica by capillary zone electrophoresis. Biomed Chromatogr 2005; 19: 250-254

33 Seitz U, Oefner PJ, Nathakarnkitkool S, Popp M, Bonn GK. Capillary electrophoretic analysis of flavonoids. Electrophoresis 1992; 13: 35-38

34 Quaglia MG, Bossù E, Donati E, Mazzanti G, Brandt A. Determination of silymarine in the extract from the dried silybum marianum fruits by high performance liquid chromatography and capillary electrophoresis. J Pharm Biomed Anal 1999; 19: 435-442

35 Marchart E, Krenn L, Kopp B. Quantification of the flavonoid glycosides in Passiflora incarnata by capillary electrophoresis. Planta Med 2003; 69: 452-456

36 Bringmann G, Kajahn I, Neusüss C, Pelzing M, Laug S, Unger M, Holzgrabe $U$. Analysis of the glucosinolate pattern of Arabidopsis thaliana seeds by capillary zone electrophoresis coupled to electrospray ionization-mass spectrometry. Electrophoresis 2005; 26: 1513-1522

37 Trute A, Nahrstedt A. Identification and quantitative analysis of phenolic compounds from the dry extract of Hedera helix. Planta Med 1997; 63: 177-179

38 Kreimeyer J, Petereit F, Nahrstedt A. Separations of flavan-3-ols and dimeric proanthocyanidins by capillary electrophoresis. Planta Med 1998; 64: 63-67

39 Sáenz-López R, Fernández-Zurbano P, Tena MT. Analysis of aged red wine pigments by capillary zone electrophoresis. J Chromatogr A 2004: 1052: 191-197

40 Emara S, Mohamed KM, Masujima T, Yamasaki K. Separation of naturally occurring triterpenoidal saponins by capillary zone electrophoresis. Biomed Chromatogr 2001; 15: 252-256

$41 \mathrm{Wu}$ X, Gong S, Bo T, Liao Y, Liu H. Determination of dissociation constants of pharmacologically active xanthones by capillary zone electrophoresis with diode array detection. J Chromatogr A 2004; 1061: 217 223

42 Li P, Li SP, Wang YT. Optimization of CZE for analysis of phytochemical bioactive compounds. Electrophoresis 2006; 27: 4808-4819

43 Walbroehl Y, Jorgenson JW. On-column UV absorption detector for open tubular capillary zone electrophoresis. J Chromatogr 1984; 315: 135143

44 Bjornsdottir I, Tjornelund J, Jansen SH. Nonaqueous capillary electrophoresis - its applicability in the analysis of food, pharmaceuticals and biological fluids. Electrophoresis 1998; 19: 2179-2186

45 Porras SP, Kenndler E. Are the asserted advantages of organic solvents in capillary electrophoresis real? A critical discussion. Electrophoresis 2005; 26: 3203-3220

46 Wang T, Wei H, Li SF. Nonaqueous capillary zone electrophoresis for separation of free fatty acids with indirect fluorescence detection. Electrophoresis 1998; 19: 2187-2192

47 Scriba GK. Non-aqueous capillary electrophoresis-mass spectrometry J Chromatogr A 2007; 1159: 28-41

48 Barthe L, Ribet JP, Pélissou M, Degude MJ, Fahy J, Duflos A. Optimization of the separation of Vinca alkaloids by nonaqueous capillary electrophoresis. J Chromatogr A 2002; 968: 241-250

$49 \mathrm{Li}$ Y, He X, Oi S, Gao W, Chen X, Hu Z. Separation and determination of strychnine and brucine in Strychnos nux-vomica L. and its preparation by nonaqueous capillary electrophoresis. J Pharm Biomed Anal 2006; 41: 400-407

50 Liu $\mathrm{Q}$ Liu Y, Li Y, Yao S. Nonaqueous capillary electrophoresis coupled with laser-induced native fluorescence detection for the analysis of berberine, palmatine, and jatrorrhizine in Chinese herbal medicines. J Sep Sci 2006; 29: 1268-1274

$51 \mathrm{Li}$ Y, Qi S, Chen X, Hu Z. Separation and determination of the anthraquinones in Xanthophytum attopvensis Pierre by nonaqueous capillary electrophoresis. Talanta 2005; 65: 15-20 
52 Li C, Chen A, Chen X, Ma X, Chen X, Hu Z. Non-aqueous capillary electrophoresis for separation and simultaneous determination of fraxin, esculin and esculetin in Cortex fraxini and its medicinal preparations. Biomed Chromatogr 2005; 19: 696-702

$53 \mathrm{Qi}$ S, Li Y, Wu S, Chen X, Hu Z. Novel nonaqueous capillary electrophoresis separation and determination of bioactive flavone derivates in Chinese herbs. J Sep Sci 2005; 28: 2180-2186

54 Demianová Z, Sirén H, Kuldvee R, Riekkola ML. Nonaqueous capillary electrophoresis separation of polyphenolic compounds in wine using coated capillaries at high $\mathrm{pH}$ in methanol. Electrophoresis 2003; 24: 4264-4271

55 Che AJ, Zhang JY, Li CH, Chen XF, Hu ZD, Chen XG. Separation and determination of active components in Radix Salviae miltiorrhizae and its medicinal preparations by nonaqueous capillary electrophoresis. J Sep Sci 2004; 27: 569-575

56 Qi S, Ding L, Tian K, Chen X, Hu Z. Novel and simple nonaqueous capillary electrophoresis separation and determination of bioactive triterpenes in Chinese herbs. J Pharm Biomed Anal 2006; 40: 35-41

57 Jensen AG, Hansen SH. Separation of hypericins and hyperforins in extracts of Hypericum perforatum L. using non-aqueous capillary electrophoresis with reversed electroosmotic flow. J Pharm Biomed Anal 2002; 27: 167-176

58 Geiser L, Veuthey JL. Nonaqueous capillary electrophoresis in pharmaceutical analysis. Electrophoresis 2007; 28: 45-57

59 Terabe S, Otsuka K, Ichikawa K, Tsuchiya A, Ando T. Electrokinetic separations with micellar solutions and open-tubular capillaries. Anal Chem 1984; 56: 111-113

60 Ganzera M, Egger C, Zidorn C, Stuppner H. Quantitative analysis of flavonoids and phenolic acids in Arnica montana L. by micellar electrokinetic capillary chromatography. Anal Chim Acta 2008; 614: 196-200

$61 \mathrm{Kuo} \mathrm{CH}$, Sun SW. Separation of bisbenzylisoquinoline alkaloids by micellar electrokinetic chromatography. Phytochem Anal 2002; 13: 6368

62 Yu L, Xu Y, Feng H, Li SF. Separation and determination of toxic pyrrolizidine alkaloids in traditional Chinese herbal medicines by micellar electrokinetic chromatography with organic modifier. Electrophoresis 2005; 26: 3397-3404

63 Mateus L, Cherkaoui S, Christen P, Oksman-Caldentey KM. Simultaneous determination of scopolamine, hyoscyamine and littorine in plants and different hairy root clones of Hyoscyamus muticus by micellar electrokinetic chromatography. Phytochemistry 2000; 54: 517-523

64 Kuzuya H, Tamai I, Beppu H, Shimpo K, Chibara T. Determination of aloenin, barbaloin and isobarbaloin in aloe species by micellar electrokinetic chromatography. J Chromatogr B 2001; 752: 91-97

65 Shang X, Yuan Z. Determination of hydroxyanthraquinoids in Rhubarb by cyclodextrin-modified micellar electrokinetic chromatography using a mixed micellar system of sodium dodecyl sulfate and sodium cholate. J Pharm Biomed Anal 2003; 31: 75-81

66 Debusschère L, Demesmay C, Rocca JL, Lachatre G, Lofti H. Separation of cardiac glycosides by micellar electrokinetic chromatography and microemulsion electrokinetic chromatography. J Chromatogr A 1997; 779: 227-233

67 Weiss DJ, Austria EJ, Anderton CR, Hompesch R, Jander A. Analysis of green tea extract supplements by micellar electrokinetic chromatography. J Chromatogr A 2006; 1117: 103-108

68 Gotti R, Furlanetto S, Pinzauti S, Carvrini V. Analysis of catechins in Theobroma cacao beans by cyclodextrin-modified micellar electrokinetic chromatography. J Chromatogr A 2006; 1112: 345-352

69 Wang SF, Ju Y, Chen XG, Hu ZD. Separation and determination of coumarins in the root bark of three citrus plants by micellar electrokinetic capillary chromatography. Planta Med 2003; 69: 483-486

70 Wang S, Dai J, Chen X, Hu Z. Identification and determination of ecdysones and flavonoids in Serratula strangulata by micellar electrokinetic capillary chromatography. Planta Med 2002; 68: 1029-1033

71 Zhang Y, Chen J, Ma XM, Shi YP. Simultaneous determination of flavonoids in Ixeridium gracile by micellar electrokinetic chromatography. J Pharm Biomed Anal 2007; 45: 742-746

72 Pietta P, Bruno A, Mauri P, Rava A. Separation of flavonol-2-O-glycosides from Calendula officinalis and Sambucus nigra by high-performance liquid and micellar electrokinetic capillary chromatography. J Chromatogr 1992; 593: 165-170

73 Song Y, Li P, Wang D, Cheng YY. Micellar electrokinetic chromatography for the quantitative analysis of flavonoids in the radix of Astragalus membranaceus var. mongholicus. Planta Med 2008; 74: 84-89
74 Karcher A, El Rassi Z. Capillary electrophoresis of glucosinolates and their degradation products. Electrophoresis 1999; 20: 3181-3189

75 Michaelsen S, Moller P, Sorensen H. Factors influencing the separation and quantitation of intact glucosinolates and desulphoglucosinolates by micellar electrokinetic capillary chromatography. J Chromatogr 1992; 608: 363-374

76 Baggett BR, Cooper JD, Hogan ET, Carper J, Paiva NL, Smith JT. Profiling isoflavonoids found in legume root extracts using capillary electrophoresis. Electrophoresis 2002; 23: 1642-1651

77 Zhang Y, Chen J, Zhao L, Shi YP. Separation and determination of isoflavones in red clover by micellar electrokinetic capillary chromatography. Biomed Chromatogr 2007; 21: 987-992

78 Cifuentes A, Bartolomé B, Gómez-Cardovés C. Fast determination of procyanidins and other phenolic compounds in food samples by micellar electrokinetic chromatography using acidic buffers. Electrophoresis 2001; 22: 1561-1567

79 Herrero-Martínez JM, Ràflos C, Rosés M, Bosch E, Lozano C, Torres JL. Micellar electrokinetic chromatography estimation of size and composition of procyanidins after thiolysis with cysteine. Electrophoresis 2003; 24: 1404-1410

80 Glöckl I, Veit M, Blaschke G. Determination of ginsenosides from Panax ginseng using micellar electrokinetic chromatography. Planta Med 2002; 68: 158-161

81 Petriska I, Polásek M, Sladkovský R. Assay of terpene alcohols in pharmacopoeial essential oils by micellar electrokinetic capillary chromatography (MEKC). Pharmazie 2006; 61: 989-993

82 Dubber MJ, Kanfer I. Application of reverse-flow micellar electrokinetic chromatography for the simultaneous determination of flavonols and terpene trilactones in Ginkgo biloba dosage forms. J Chromatogr A 2006; 1122: 266-274

83 Huie CW. Recent applications of microemulsion electrokinetic chromatography. Electrophoresis 2006; 27: 60-75

84 Pomponio R, Gotti R, Luppi B, Cavrini V. Microemulsion electrokinetic chromatography for the analysis of green tea catechins: effect of the cosurfactant on the separation selectivity. Electrophoresis 2003; 24: 1658-1667

85 Huang HY, Lien WC, Chiu CW. Comparison of microemulsion electrokinetic chromatography and micellar electrokinetic chromatography methods for the analysis of phenolic compounds. J Sep Sci 2005; 28: 973-981

86 Vanhoenacker G, Rong H, De Keukeleire D, Baeyens W, Van Der Weken G, Sandra $P$. Simultaneous analysis of hop acids and prenylated flavanones by microemulsion electrokinetic chromatography with diode array detection. Biomed Chromatogr 2000; 14: 34-36

87 Aiken JH, Huie CW. Use of a microemulsion system to incorporate a lipophilic chiral selector in electrokinetic capillary chromatography. Chromatographia 1993; 35: 448-503

88 Sun SW, Yeh PC. Analysis of rhubarb anthraquinones and bianthrones by microemulsion electrokinetic chromatography. J Pharm Biomed Anal 2005; 36: 995-1001

89 Zhang J, Xie J, Liu J, Tian J, Chen X, Hu Z. Microemulsion electrokinetic chromatography with laser-induced fluorescence detection for sensitive determination of ephedrine and pseudoephedrine. Electrophoresis 2004: 25: 74-79

90 Wenhua G, Yaowen C, Yegao Y, Xingguo C, Zhide H. Separation and determination of two sesquiterpene lactones in Radix inulae and Liuwei Anxian San by microemulsion electrokinetic chromatography. Biomed Chromatogr 2004; 18: 826-832

91 Bo T, Yang X, Li KA, Xu L, Liu H. Comparison of micellar electrokinetic chromatography and microemulsion electrokinetic chromatography for separation of pharmacologically active xanthones from Securidaca inappendiculata. J Sep Sci 2003; 26: 133-136

92 Scherz H, Huck CW, Bonn GK. CEC and EKC of natural compounds. Electrophoresis 2007; 28: 1645-1657

93 Lai EP, Dabek-Zlotorzynska E. Separation of theophylline, caffeine and related drugs by normal-phase capillary electrochromatography. Electrophoresis 1999; 20: 2366-2372

$94 \mathrm{Li} \mathrm{Y}$, Liu H, Ji X, Li J. Optimized separation of pharmacologically active anthraquinones in Rhubarb by capillary electrochromatography. Electrophoresis 2000; 21: 3109-3115

95 Ganzera M, Stöggl WM, Bonn GK, Khan IA, Stuppner H. Capillary electrochromatography of boswellic acids in Boswellia serrata Roxb. J Sep Sci 2003; 26: 1383-1388

96 Lurie IS, Meyers RP, Conver TS. Capillary electrochromatography of cannabinoids. Anal Chem 1998; 70: 3255-3260 
97 Desiderio C, De Rossi A, Sinibaldi M. Analysis of flavanone-7-0-glycosides in citrus juices by short-end capillary electrochromatography. J Chromatogr A 2005; 1081: 99-104

98 Starkey JA, MechrefY, Byun CK, Steinmetz R, Fuqua JS, Pescovitz OH, Novotny MV. Determination of trace isoflavone phytoestrogens in biological materials by capillary electrochromatography. Anal Chem 2002; 71: 5998-6005

99 Abidi SL. Capillary electrochromatography of sterols and related steryl esters derived from vegetable oils. J Chromatogr A 2004; 1059: 199208

100 Cherkaoui S, Cahours X, Veuthey JL. Analysis of selected withanolides in plant extracts by capillary electrochromatography and microemulsion electrokinetic chromatography. Electrophoresis 2003; 24: $336-$ 342

101 Wätzig H, Degenhardt M, Kunkel A. Strategies for capillary electrophoresis: method development and validation for pharmaceutical and biological applications. Electrophoresis 1998; 19: 2695-2752

102 Lloyd DK, Wätzig H. Sodium dodecyl sulfate solution is an effective between-run rinse for capillary electrophoresis of samples in biological matrices. J Chromatogr B 1995; 663: 400-405

$103 \mathrm{Wu} N$, Clausen AM. Fundamental and practical aspects of ultrahigh pressure liquid chromatography for fast separations. J Sep Sci 2007; 30: 1167-1182

104 Hemström P, Irgum K. Hydrophilic interaction chromatography. J Sep Sci 2006; 29: 1784-1821

105 Dräger B. Analysis of tropane related alkaloids. J Chromatogr A 2002; 978: 1-35

106 Orlandini S, Giannini I, Pinzauti S, Furlanetto S. Multivariate optimisation and validation of a capillary electrophoresis method for the analysis of resveratrol in a nutraceutical. Talanta 2008; 74: 570-577

107 Olivares JA, Nguyen NT, Yonker CR, Smith RD. On-line mass spectrometric detection for capillary zone electrophoresis. Anal Chem 1987; 59: $1230-1232$

108 Smith RD, Barinaga CJ, Udseth HR. Improved electrospray ionization interface for capillary zone electrophoresis-mass spectrometry. Anal Chem 1988; 60: 1948-1952

109 Banks JF. Recent advances in capillary electrophoresis/electrospray/ mass spectrometry. Electrophoresis 1997; 18: 2255-2266

110 Hsieh FY, Cai J, Henion J. Determination of trace impurities of peptides and alkaloids by capillary electrophoresis-ion spray mass spectrometry. J Chromatogr A 1994; 679: 206-211

111 Henion JD, Mordehai AV, Cai J. Quantitative capillary electrophoresis ion spray mass spectrometry on a benchtop ion trap for the determination of isoquinoline alkaloids. Anal Chem 1994; 66: 2103-2109

112 Unger M, Stöckigt D, Belder D, Stöckigt J. Alkaloid determination in crude extracts from cortex quebracho and opium applying capillary electrophoresis and capillary electrophoresis-mass spectrometry coupling. Pharmazie 1997; 52: 691-695

113 Stöckigt D, Unger M, Belder D, Stöckigt J. Analysis of Rauwolfia alkaloids employing capillary electrophoresis-mass spectrometry. Nat Prod Lett 1997; 9: 265-272

114 Sturm S, Seger C, Stuppner H. Analysis of Central European Corydalis species by nonaqueous capillary electrophoresis-electrospray ion trap mass spectrometry. J Chromatogr A 2007; 1159: 42-50

115 Bianco G, Schmitt-Kopplin P, De Benedetto G, Kettrup A, Cataldi TR. Determination of glycoalkaloids and relative aglycones by nonaqueous capillary electrophoresis coupled with electrospray ionization-ion trap mass spectrometry. Electrophoresis 2002; 23: 2904-2912

116 Unger M, Dreyer M, Specker S, Laug S, Pelzing M, Neusüss C, Holzgrabe $U$, Bringmann $G$. Analytical characterisation of crude extracts from an African Ancistrocladus species using high-performance liquid chromatography and capillary electrophoresis coupled to ion trap mass spectrometry. Phytochem Anal 2004; 15: 21-26

117 Wang S, Qu H, Cheng Y. NACE-ESI-MS combined with on-line concentration for high-sensitivity analysis of quinolizidine alkaloids. Electrophoresis 2007; 28: 1399-1406

118 Arráez-Román D, Zurek G, Bässmann C, Segura-Carretero A, FernándezGutiérrez A. Characterisation of Atropa belladonna L. compounds by capillary electrophoresis-electrospray ionization-time of flight-mass spectrometry and capillary electrophoresis-electrospray ionizationion trap-mass spectrometry. Electrophoresis 2008; 29: 2112-2116
119 Simó C, Barbas C, Cifuentes A. Capillary electrophoresis-mass spectrometry in food analysis. Electrophoresis 2005; 26: 1306-1318

120 Vanhoenacker G, DeVilliers A, Lazou K, DeKeukeleire D, Sandra P. Comparison of high-performance liquid chromatography - mass spectroscopy and capillary electrophoresis - mass spectroscopy for the analysis of phenolic compounds in diethyl ether extracts of red wines. Chromatographia 2001; 54: 309-315

121 Rodat A, Gavard P, Couderc F. Improving detection in capillary electrophoresis with laser induced fluorescence via a bubble cell capillary and laser power adjustment. Biomed Chromatogr 2009; 23: 42-47

122 Driedger DR, LeBlanc RJ, LeBlanc EL, Sporns P. A capillary electrophoresis laser-induced fluorescence method for analysis of potato glycoalkaloids based on a solution-phase immunoassay. 2. Performance evaluation. J Agric Food Chem 2000; 48: 4079-4082

123 Zhang ZL, Liu X, Li DF, Lu YT. Determination of jasmonic acid in bark extracts from Hevea brasiliensis by capillary electrophoresis with laser-induced fluorescence detection. Anal Bioanal Chem 2005; 382 : 1616-1619

124 Wang W, Tang J, Wang S, Zhou L, Hu Z. Method development for the determination of coumarin compounds by capillary electrophoresis with indirect laser-induced fluorescence detection. J Chromatogr A 2007; 1148: 108-114

125 Geng CH, Wang WY, Lin M, Ye JN. Determination of flavonoids in Plumula nelumbini by micellar electrokinetic capillary electrophoresis with electrochemical detection. J Capill Electrophor Microchip Technol 2007; 10: 57-61

126 Yu LS, Xu XQ Huang L, Ling JM, Chen GN. Separation and determination of flavonoids using microemulsion EKC with electrochemical detection. Electrophoresis 2008; 29: 726-733

127 Simpson Jr SL, Quirino JP, Terabe S. On-line sample pre-concentration in capillary electrophoresis. Fundamentals and applications. J Chromatogr A 2008; 1184; 504-541

$128 \mathrm{Zhu}$ J, Yu K, Chen X, Hu Z. Comparison of two sample pre-concentration strategies for the sensitivity enhancement of flavonoids found in Chinese herbal medicine in micellar electrokinetic chromatography with UV detection. J Chromatogr A 2007; 1166: 191-200

129 Yu L, Xu X, Huang L, Lin J, Chen G. Microemulsion electrokinetic chromatography coupling with field amplified sample injection and electroosmotic flow suppressant for analysis of some quinolizidine alkaloids. J Chromatogr A 2008; 1198: 220-225

130 Unger M, Stöckigt J. Improved detection of alkaloids in crude extracts applying capillary electrophoresis with field amplified sample injection. J Chromatogr A 1997; 791: 323-331

131 Petr J, Vitkocvá K, Ranc V, Znaleziona J, Maier V, Knob R, SevcikJ. Determination of some phenolic acids in Majorana hortensis by capillary electrophoresis with online electrokinetic pre-concentration. J Agric Food Chem 2008; 56: 3940-3944

132 Quirino JP, Otsuka K, Terabe S. On-line concentration of neutral analytes for micellar electrokinetic chromatography VI. Stacking using reverse migrating micelles and a water plug. J Chromatogr B 1998; 714: $29-38$

133 Quirino JP, Terabe S. Exceeding 5000-fold concentration of dilute analytes in micellar electrokinetic chromatography. Science 1998; 282: 465-468

134 Huang HY, Hsieh SH. Analyses of tobacco alkaloids by cation-selective exhaustive injection sweeping microemulsion electrokinetic chromatography. J Chromatogr A 2007; 1164: 313-319

135 Huang HY, Huang IY, Liang HH, Lee S. Sample stacking for the analysis of catechins by microemulsion EKC. Electrophoresis 2007; 28: 17351743

136 Huang HY, Lien WC, Huang IY. Anion-selective exhaustive injectionsweeping microemulsion electrokinetic chromatography. Electrophoresis 2006; 27: 3202-3209

137 Hsieh MC, Lin CH. On-line identification of trans-resveratrol in red wine using a sweeping technique combined with capillary electrophoresis/77 K fluorescence spectroscopy. Electrophoresis 2004; 25: 677-682

138 Zhou M, Ma YJ, Ren XN, Zhou XY, Li L, Chen H. Determination of sinomenine in Sinomenium acutum by capillary electrophoresis with electrochemiluminescence detection. Anal Chim Acta 2007; 587: 104109 